\title{
PERSEPSI PEMANDU/PETANDU TERHADAP PEMBENTUKAN KELOMPOK IPPHTI, JAWA BARAT
}

\author{
Cliffton R. Bonzo, Amri Jahi, dan \\ Rama B. Radhakrishna
}

\begin{abstract}
Abstrak
IPPHTI (Ikatan Petani Pengendalian Hama Terpadu Indonesia) nasional berawal dari kegiatan-kegiatan terkait dengan Sekolah Lapangan (SL). Tujuan studi ini adalah meneliti persepsi pemandu/petandu IPPHTI berkaitan dengan faktor-faktor yang mempengaruhi pembentukan kelompok IPPHTI, Jawa Barat. Profil demografik dari survei menunjukkan mayoritas laki-laki (partisipasi wanita 30\%), bersuku Sunda, berpendidikan SD dan telah menamatkan SL. Faktor-faktor yang mempengaruhi pembentukan kelompok IPPHTI adalah tersedianya sumberdaya manusia (SDM) dan adanya jaringan organisasi-organisasi. Kategori ilmu dan pengetahuan membuktikan ada kaitan dengan keinginan tahu dan hak-hak asasi manusia khususnya hak milik tanah. Jenis kelaminan, kesukuan, status kepemimpinan, dan penggarapan atas tanah tidak membuktikan adanya perbedaan berarti dalam persepsi antara berbagai status pendidikan dan pembentukan IPPHTI. Meskipun demikian, terdapat perbedaan berarti dalam persepsi antara berbagai status pendidikan dan pembentukan kelompok IPPHTI. Para pemandu/petandu siap berdiskusi dengan pemerintah setempat dan Dinas Pertanian terkait mengenai hasil survei ini. Hasil dari survei, yang dilaksanakan April 2004, sudah dilaporkan ke responden (IPPHTI, Jawa Barat). Diskusi yang berlangsung meliputi tiga pertanyaan: 1. Mengapa status pendidikan mempengaruhi hasil survei? 2. Apakah dasar dari korelasi antara pengetahuan yang diperoleh dan hak milik tanah? 3. Mengapa SDM lebih bernilai daripada bantuan ekonomi dalam mengembangkan IPPHTI? Pendapat yang muncul dari diskusi-diskusi adalah apabila pelatihan SDM tersedia, maka sumberdaya ekonomi dari pemerintah dan swasta serta penelitian universitas akan lebih baik dimanfaatkan yang dilatih SL. Memperoleh informasi yang secara konkret dapat memperbaiki penghidupan petani selalu menjadi tujuan utama dari IPPHTI.
\end{abstract}

Kata Kunci: Sekolah Lapangan, Pengendalian Hama Terpadu, Pembentukan Kelompok

\section{Pendahuluan}

IPPHTI (Ikatan Petani Pengendalian Hama Terpadu Indonesia) nasional berawal dari kegiatan-kegiatan terkait dengan Sekolah Lapangan (SL). Food and Agriculture Organization (FAO) telah kerja sama dengan program SL sejak 1989 hingga 1999. Selama dekade ini telah dilaksanakan 75.000 SL, dilatihnya 1,1 juta petani dan diperdayakannya 29.500 pemandu serta petani-pemandu (petandu) agar mereka bisa memandu SL yang lainnya (FAO, 2001).
Pembentukan kelompok merupakan “perlembagaan" suatu konsep (Bunch, 2000). Konsep perlembagaan adalah sama dengan kenaikan tingkat organisasi (Dilts, 2001). Salah satu perhatian besar yang ditarik dari satu konferensi SLPHT yang berada di Yogyakarta, Indonesia, Oktober, 2002 (CIPUPWARD, 2003) adalah isu kenaikan tingkat organisasi SLPHT ke IPPHTI. Diskusi lokakarya di Yogyakarta tentang keberlangsungan SLPHT menyimpulkan bahwa lebih banyak penelitian diperlukan dalam rangka kenaikan tingkat organisasi 
(Dilts, 2001) melalui pembentukan ikatan petani.

Tujuan studi adalah memeriksa persepsi para pemimpin SLPHT tentang faktor-faktor yang mempengaruhi perkembangan kelompok IPPHTI, Jawa Barat. Tujuan-tujuan studi di bahwa ini mengendalikan penelitian ini: 1) Menunjukkan gambaran ciri-ciri kependudukan para peserta. 2) Mengukur persepsi para peserta tentang faktor-faktor yang menyebabkan perkembangan IPPHTI. 3) Mengukur sejauh mana ilmu sien pertanian yang diperoleh penting untuk perkembangannya. 4) Mengukur hubungan perkembangan IPPHTI dan ciri-ciri kependudukan.

\section{Metode $^{2}$ dan Tatacara ${ }^{2}$}

Studi ini memakai desain deskriptif-korelasional. Instrumentasi pengumpulan data untuk studi ini adalah survei (Uphoff, 1998). Secara logistik, untuk mensurvei seluruh penduduk SLPHT dari IPPHTI, Jawa Barat adalah mustahil. Patton (1997) mengusulkan agar evaluasi lebih berguna kalau kita usahakan mensurvei kepemimpinan organisasi yang bikin keputusan-keputusan tentang kenaikan tingkat organisasi. Jadi, inisiatipinisiatip untuk mensurvei diarahkan terhadap para kepala SLPHT setempat atau IPPHTI di kecamatan. Para kepala tersebut dan para pemimpin dilatih di SLPHT, kursus ToT atau dua-duanya (FAO, 2001).

Koordinator Umum IPPHTI, Jawa Barat, diminta mencari calon peserta survei yang dianggap pemimpin SLPHT untuk studi ini. Para kepala kecamatan diminta mencari tempat pertemuan survei dimana ada 40 pemimpin yang bisa hadir di satu tempat pertemuan untuk mengisi surveinya. Enam kabupaten dan dua kecamatan per kabupaten ditunjuk oleh Koordinator Umum IPPHTI didasarkan ukuran aktif atau tidak aktif dalam kegiatan-kegiatan ikatan petani setempat (6 Kab. X 2 Kec. X 40 peserta). Akibatnya, sesudah pembersihan data, jumlah peserta yang terlibat dalam studi adalah 347 orang. Dengan demikian, sampel ini adalah dengan maksud tertentu, tidak menyusahkan, dan tidak sembarangan.
Ketika suatu sampel sembarangan diambil untuk rangka pendudukan yang nyata dan ditentukan dengan baik, tes-tes parametrik bisa digunakan (Urdan, 2001; Huck, 2000; Stockburger, 1998). Rangka pendudukan tidak bisa ditentukan dalam studi ini, tetapi Huck (2000) mengusulkan bahwa ketika rangka pendudukan mustahil ditentukan, maka satu perkiraan yang terbaik melalui suatu sampel yang mewakili rangka pendudukan itu jadi suatu refleksi daripada pendudukan yang nyata (pp. 112-115). Dengan dasar pembenaran itu, peniliti ini bisa memakai statistik inferensial agar bisa mencari hubungan $^{2}$ di antara kelompok ${ }^{2}$, kategori ${ }^{2}$ dan variabel $^{2}$.

Validity atau kebenaran instrumen ditentukan dengan panel ahli 12 orang termasuk fakultas Universitas Penn State serta Dr. Amri Jahi, Institut Pertanian Bogor, Indonesia. Uji coba instrumen tes dilaksanakan di dua kecamatan di Garut untuk mengkirakan reliability (hal tahan uji). Reliability dari dua kecamatan tersebut dan studi akhir dikira pantas diterima (Cronbach alpha dari 0,84 ke 0,86).

\section{Kesimpulan Temuan ${ }^{2}$ sesuai dengan Pertanyaan $^{2}$ Reset}

Pertanyaan Reset (PR) \# 1: Bagaimana profil demografik IPPHTI, Jawa Barat?

Peserta survei IPPHTI adalah 90\% Sunda dan 47\% berpendidikan Sekolah Dasar. $30 \%$ adalah wanita. $60 \%$ para pemimpin menanam kurang daripada 0,5 hectare sawah. Kira-kira $66 \%$ pemimpin adalah alumni SL dan hampir $10 \%$ dilatih ToT.

PR \# 2: Faktor $^{2}$ Capital apa yang menyambung dengan pembentukan IPPHTI?

Satu instrumen yang mempunyai butir yang ke 32 dan yang memakai skala empat poin $(0=$ kurang baik, $1=$ perlu perbaikan, tapi masih bisa berfungsi, $2=$ baik, dan $3=$ keadaan yang terbaik) dipakai untuk menunjukkan faktor $^{2}$ yang mempengaruhi pembentukan kelompok IPPHTI. Faktor ${ }^{2}$ ini dikumpulkan dalam lima kategori capital, yaitu sosial, kemanusiaan, alamiah, keuangan/fisik, dan ilmu (Tabel 1). 
Tabel 1: Faktor ${ }^{2}$ Capital Yang Mempengaruhi Pembentukan Kelompok

\begin{tabular}{|c|c|c|c|c|}
\hline Capital & Variabel Survei & $\mathbf{n}$ & $\mathbf{M}^{*}$ & SD \\
\hline \multirow[t]{10}{*}{ Sosial } & Tindakan kelompok lebih bernilai keuntungan pribadi & 344 & 2,8 & 0,68 \\
\hline & Anggaran dasar dan ramah tangga IPPHTI & 345 & 2,3 & 0,79 \\
\hline & Penyebarluasan program IPPHTI & 342 & 2,3 & 0,80 \\
\hline & Hubungan IPPHTI dengan Pemda/Dinas & 344 & 2,4 & 0,79 \\
\hline & Hubungan IPPHTI dengan organisasi setempat lain & 345 & 2,1 & 0,92 \\
\hline & Penerimaan dan Dukungan masyarakat pada IPPHTI & 340 & 2,4 & 0,70 \\
\hline & Akses IPPHTI pada sumberdaya & 347 & 2,4 & 0,79 \\
\hline & Dampak sosial kegiatan IPPHTI pada masyarakat & 342 & 2,5 & 0,87 \\
\hline & Keseimbangan manfaat ekonomi / social di masyarakat & 345 & 2,6 & 0,79 \\
\hline & Total & & 2,4 & $\mathbf{0 , 7 9}$ \\
\hline \multirow[t]{12}{*}{ Kemanusian } & Cara pengambilan keputusan & 340 & 2,6 & 0,56 \\
\hline & Partisipasi anggota dalam pembuatan keputusan IPPHTI & 344 & 2,6 & 0,72 \\
\hline & Partisipasi wanita dalam pengelolaan IPPHTI & 344 & 2,3 & 0,65 \\
\hline & Rencana kerja IPPHTI disadari anggota & 344 & 2,3 & 0,74 \\
\hline & Kejelasan tujuan IPPHTI & 345 & 2,4 & 0,79 \\
\hline & Dukungan IPPHTI pada Group Promoter & 342 & 1,9 & 0,94 \\
\hline & Ketergantungan IPPHTI pada Group Promoter & 341 & 2,0 & 0,93 \\
\hline & Kemandirian IPPHTI & 347 & 2,1 & 0,86 \\
\hline & Kemampuan IPPHTI menolak tekanan dari pihak lain & 347 & 2,4 & 0,80 \\
\hline & Keberlangsungan IPPHTI pada masa depan & 343 & 2,3 & 0,87 \\
\hline & Partisipasi anggota dalam monitoring \& evaluasi kelompok & 342 & 2,4 & 0,84 \\
\hline & Total & & 2,3 & 0,79 \\
\hline \multirow[t]{4}{*}{ Alamiah } & Program-program perlindungan lingkungan hidup & 342 & 2,5 & 0,70 \\
\hline & Partisipasi IPPHTI dalam pengembangan pertanian & 346 & 2,3 & 0,72 \\
\hline & Cara petani mengevaluasi prestasi kerja mereka & 345 & 2,0 & 0,96 \\
\hline & - & & 2,3 & $\mathbf{0 , 7 9}$ \\
\hline Keuangan/ & Promosi diversifikasi ekonomi & 345 & 2,0 & 1,0 \\
\hline \multirow[t]{5}{*}{ Fisik } & Bantuan kepada anggota untuk peroleh pinjaman produksi & 347 & 1,5 & 1,1 \\
\hline & Pengembangan tabungan kelompok untuk pinjaman darurat & 345 & 1,6 & 1,2 \\
\hline & Pengelolaan dan pembukuan keuangan & 345 & 2,3 & 0,96 \\
\hline & Pengamanan dana kelompok & 344 & 1,7 & 1,1 \\
\hline & Total & & 1,8 & 1,1 \\
\hline \multirow[t]{5}{*}{ Ilmu } & Cara petani mencoba-coba ilmu \& teknologi baru & 345 & 2,2 & 0,79 \\
\hline & Akses petani pada teknologi baru & 342 & 2,0 & 0,90 \\
\hline & Penggunaan teknologi asli setempat & 346 & 2,2 & 0,77 \\
\hline & Diseminasi teknologi yang dianjurkan oleh IPPHTI & 346 & 2,1 & 0,73 \\
\hline & Total & & 2,1 & $\mathbf{0 , 8 0}$ \\
\hline
\end{tabular}

*mean scale: $0=$ kurang baik, $1=$ perlu perbaikan, tapi masih bisa berfungsi, 2 = baik, dan 3 = keadaan yang terbaik

Secara keserurunan, Keuntungan sostal IKaran IIII adaran untuK IIndakan kolektip. menerima mean yang tertinggi $(M=2,4$, Sebaliknya, para peserta melihat variabel $S D=0,79)$ dan keuntungan keuangan mean "IPPHTI menolong mencari kredit" $(M=1,5$, yang terrendah $(M=1,8, S D=1,1)$. Variabel sosial "Tindakan kolektif bernilai" menerima mean yang tertinggi $(M=2,8, S D=0,68)$. Hal itu mengusulkan bahwa para peserta mengerti dengan jelas alasan mereka bergabung dengan $S D=1,1)$ seperti sesuatu yang perlu berubah.

Instrumen yang mempunyai butir yang ke 16 dipakai untuk mengukur kepentingan pembentukan kelompok dari persepsi para peserta. 16 butir ini dikelompok dalam tiga 
kategori-Faktor ${ }^{2}$, Tantangan $^{2}$ dan Alasan $^{2}$ - diukur dengan skala enam poin $(0$ $=$ tidak tahu, $1=$ mungkin tidak penting, $2=$ mungkin penting/mungkin ngak penting, $3=$ penting, $4=$ mungkin penting, $5=$ sangat penting) (Tabel 2).
Secara seluruhnya, butir-butir 14 daripada butir-butir 16 di dimensi pembentukan kelompok bernilai 4,0 ke atas. Nilai ini menunjukkan bahwa para petani melihat butir-butir tersebut seperti "penting" atau "sangat penting."

Tabel 2: Dimensi Pembentukan Kelompok

\begin{tabular}{|c|c|c|c|c|}
\hline $\begin{array}{l}\text { Pertanyaan } \\
\text { Survei }\end{array}$ & Bagian Pertanyaan & $\mathbf{n}$ & $\mathbf{M}^{*}$ & SD \\
\hline \multirow{6}{*}{$\begin{array}{l}\text { Faktor }^{2} \text { dalam } \\
\text { pembentukan } \\
\text { kelompok }\end{array}$} & Gaya kepemimpinan & 342 & 4,8 & 0,6 \\
\hline & Bantuan pekerja sukarela & 345 & 4,5 & 0,78 \\
\hline & Koordinasi air untuk pengairan & 342 & 4,7 & 0,8 \\
\hline & $\begin{array}{l}\text { Memperjuangkan hak milik } \\
\text { tanah }\end{array}$ & 344 & 4,6 & 0,85 \\
\hline & Pengendalian harga pasar & 344 & 4,7 & 0,86 \\
\hline & Ilmu pengetahuan pertanian & 345 & 4,8 & 0,55 \\
\hline & \multicolumn{2}{|l|}{ Total } & 4,7 & 0,74 \\
\hline \multirow{6}{*}{$\begin{array}{l}\text { Tantangan }^{2} \\
\text { dalam } \\
\text { pembentukan } \\
\text { kelompok }\end{array}$} & Otonomi daerah & 344 & 4,2 & 1,2 \\
\hline & Status hukum organisasi & 342 & 4,3 & 1,1 \\
\hline & Biaya keanggotaan & 344 & 3,8 & 1,2 \\
\hline & Biaya permulaan ditanggung & 343 & 3,8 & 1,4 \\
\hline & $\begin{array}{l}\text { Kematangan kelompok tani dua } \\
\text { tahun sebelum bergabung ikatan }\end{array}$ & 325 & 4,1 & 1,4 \\
\hline & Total & & 4,0 & 1,2 \\
\hline \multirow{6}{*}{$\begin{array}{l}\text { Alasan }^{2} \text { anda } \\
\text { menjadi anggota } \\
\text { ikatan }\end{array}$} & $\begin{array}{l}\text { Kemampuan IPPHTI daripada } \\
\text { kelompok yang lain }\end{array}$ & 342 & 4,6 & 0,47 \\
\hline & Tujuan IPPHTI lebih berharga & 344 & 4,8 & 0,47 \\
\hline & $\begin{array}{l}\text { Harga kebutuhan pertanian lebih } \\
\text { murah }\end{array}$ & 340 & 4,5 & 1,1 \\
\hline & $\begin{array}{l}\text { Harga pasar produksi anda lebih } \\
\text { tinggi }\end{array}$ & 338 & 4,3 & 1,3 \\
\hline & $\begin{array}{l}\text { IPPHTI memperjuangkan hak } \\
\text { milik tanah }\end{array}$ & 343 & 4,1 & 1,4 \\
\hline & Total & & 4,5 & 1,0 \\
\hline & \multicolumn{4}{|c|}{ *mean scale: $\begin{aligned} 0=\text { tidak tahu, } 1=\text { mungkin tidak penting, } \\
2=\text { mungkin penting/mungkin ngak penting, } 3= \\
\text { penting, } 4=\text { mungkin penting, } 5=\text { sangat penting }\end{aligned}$} \\
\hline
\end{tabular}

Nilai mean yang terrendah $(3,8)$ dilaporkan untuk dua butir di kategori Tantangan" ("biaya keanggotaan" dan "biaya permulaan ditanggung"). Nilai mean yang tertinggi $(4,8)$ dilaporkan untuk dua butir ("gaya kepemimpinan" dan "ilmu pengetahuan pertanian") di kategori Faktor ${ }^{2}$ dan satu butir ("tujuan IPPHTI lebih berharga") dalam kategori Alasan' (Tabel 2).
Pearson $r$ korelasi dikalkulasikan agar mencari hubungan ${ }^{2}$, kalau ada, di antara faktor $^{2}$ capital (sosial, kemanusiaan, alamiah, fisik/ keuangan, dan ilmu) dan dimensi pembentukan kelompok (Faktor ${ }^{2}$, Tantangan', dan Alasan ${ }^{2}$ ). Skala yang disediakan Davis dipakai untuk menjelaskan berapa besarnya hubungan ${ }^{2}$ di antara variabel $^{2}$. 
Tabel 3: Hubungan ${ }^{2}$ di antara Faktor ${ }^{2}$ Capital dan Dimensi Pembentukan Kelompok

\begin{tabular}{l|lll}
\hline Capital $^{2}$ & Factor $^{2}$ & Tantangan $^{2}$ & Alasan $^{2}$ \\
\hline Sosial & 0,092 & $0,165^{* *}$ & $0,242^{* *}$ \\
Kemanusian & 0,016 & $0,118^{*}$ & $0,278^{* *}$ \\
Alamiah & $-0,044$ & 0,047 & $0,157 * *$ \\
Keuangan & $-0,023$ & 0,087 & $0,171 * *$ \\
Ilmu & $-0,015$ & $-0,009$ & $0,157 * *$ \\
\hline \multicolumn{4}{r}{ ** Korelasi bernilai di taraf $\mathrm{p} \leq 0,01$ (2-tailed). } \\
& $*$ Korelasi bernilai di taraf $\mathrm{p} \leq 0,05$ (2-tailed).
\end{tabular}

Tabel 4: Korelasi di antara Ilmu dan Variabel $^{2}$ Pembentukan Kelompok

\begin{tabular}{|c|c|c|c|c|}
\hline Variabel & $\begin{array}{l}\text { koordinasi } \\
\text { (hak air) }\end{array}$ & $\begin{array}{c}\text { otonomi } \\
\text { daerah }\end{array}$ & $\begin{array}{c}\text { kelompok } \\
\text { kuat }\end{array}$ & $\begin{array}{c}\text { hak milik } \\
\text { tanah } \\
\text { (advokasi) }\end{array}$ \\
\hline $\begin{array}{r}\text { - ilmu men- } \\
\text { coba-coba }\end{array}$ & & $-0,142 * *$ & $0,111^{*}$ & $\mathbf{0 , 1 6 0 * *}$ \\
\hline $\begin{array}{l}\text { - teknologi } \\
\text { baru }\end{array}$ & & & & $0,145 * *$ \\
\hline $\begin{array}{l}\text { - ilmu asli } \\
\text { setempat }\end{array}$ & $-0,123 *$ & & & $0,145 * *$ \\
\hline $\begin{array}{l}\text { - ilmu } \\
\text { seluruhnya }\end{array}$ & & & $0,130 *$ & $\mathbf{0 , 1 7 0} * *$ \\
\hline
\end{tabular}

PR \#3: Sejauh mana ilmu sien pertanian yang diperoleh penting untuk perkembangannya?

Suatu program baru akan lebih banyak dinilai oleh masyarakat kalau mereka mempertimbangkan ilmu asli setempat dalam program itu. Maka dari itu, tindakan kolektif (Friere, 1970) akan lebih banyak menyatakan akibat yang didugakan karena desain program melibatkan ilmu asli setempat. Kelompokkelompok yang memulai dari kegiatankegiatan tersebut akan lebih antusias.

Hubungan $^{2}$ rendah ke moderat (sedang), bernilai di taraf $p \leq 0,01$, ditemukan di antara semua faktor ${ }^{2}$ capital dan kategori Alasan $^{2}$ dalam dimensi pembentukan kelompok (Tabel 3). Capital sosial $(\mathrm{r}=0,242)$ dan capital kemanusiaan $(\mathrm{r}=0,278)$ bernilai "moderat" terhadap kategori Alasan² dalam dimensi pembentukan kelompok. Demikian juga, hubungan ${ }^{2}$ yang rendah, bernilai di taraf $\mathrm{p} \leq 0,01$, ditemukan di antara capital sosial $(\mathrm{r}=0,165)$ dan capital kemanusiaan $(\mathrm{r}=0,118$, $\mathrm{p} \leq 0,05)$ dan Tantangan $^{2}$ dalam dimensi pembentukan kelompok. Bagaimanapun, tidak ada hubungan ${ }^{2}$ yang nilai yang berarti di antara dimensi pembentukan kelompok dan lima faktor capital (Tabel 3).

Korelasi rendah tetapi cukup bernilai dengan taraf $p \leq 0,01$ di antara variabel hak milik tanah, suatu isu keadilan sosial dalam kategori Alasan ${ }^{2}$ dari dimensi pembentukan kelompok, dan variabel-variabel ilmu asli setempat, teknologi baru, dan ilmu eksperimen mencoba-coba (jajaran $\mathrm{r}=0,160$ 
hingga $r=0,144)$. Rupanya ada hubungan di antara ilmu dan isu advokasi di daerah hak milik tanah (Tabel 4). secara berbeda-beda. Kesimpulannya adalah pendidikannya yang berbeda-beda berhubungan dengan pembentukan kelompok,

\section{Status Pendidikan dan Dimensi ${ }^{2}$ Pembentukan Kelompok}



Faktor $^{2}$

Tantangan $^{2}$

Alasan $^{2}$

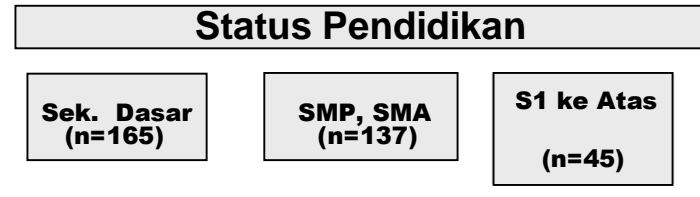

$4,61^{*}$

4,75

4,80

$F=4,36 ; p<0,05$

3,99

4,08

4,17

4,47

* Mean dikalkulasikan dari skala 0--5

Gambaran 2: Hasil Tes ANOVA

PR \#4: Pembentukan IPPHTI dan ciri-ciri khas demografik berhubungan bagaimana?

Perbedaan rata-rata yang cukup besar ada di antara status pendidikan para peserta dan tiga dimensi-Faktor ${ }^{2}$, Tantangan ${ }^{2}$, dan Alasan 2 - pembentukan kelompok (Gambaran 2). Para pemimpin yang lulus dari SMA melihat butir-butir di dimensi Faktor ${ }^{2}$ bernilai lebih penting $(M=4,8)$ dari pada para pemimpin yang lulus dari SD $(M=4,61)$. Para pemimpin yang berpendidikan SMP ke atas melihat dimensi pembentukan kelompok Tantangan $^{2}$ sebagai lebih penting $(M=4,19$ and $M=4,08$ berturut-turut) dari pada para pemimpin yang berpendidikan SD $(M=3,98)$. Akhirnya, para pemimpin yang lulus SMA melihat butir-butir dalam dimensi Alasan ${ }^{2}$ sebagai lebih penting $(M=4,49)$ daripada para pemimpin yang berpendidikan $\mathrm{S} 1$ ke atas $(\mathrm{M}=4,29)$.

Secara seluruhnya, tidak ada pola yang jelas yang dapat menjelaskan mengapa para pemimpin dari berbagai status pendidikan bernilai dimensi pembentukan kelompok tetapi pengaruhnya tidak dapat dijelaskan dari studi ini.

\section{Tindak Lanjut Studi}

Hasil Survei yang dilaksanakan April 2004 sudah dilaporkan di IPPHTI, Jawa Barat. Diskusi yang berlangsung meliputi tiga pertanyaan: Tujuan diskusi itu adalah untuk menemukan mengapa beberapa kesimpulan tidak sesuai dengan kesimpulan yang terduga.

\section{Pertanyaan $^{2}$ Reset Tindak Lanjut dari Survei IPPHTI}

1. Mengapa status pendidikan mempengaruhi hasil survei?

2. Apakah dasar dari korelasi antara pengetahuan yang diperoleh dan hak milik tanah?

3. Mengapa SDM lebih bernilai daripada bantuan ekonomi dalam mengembangkan IPPHTI? 


\section{Ringkasan}

Jawaban Pertanyaan Reset (JPR) \#1: Peserta yang berpendidikan SD akan menjawab sesuai dengan ilmu praktek mereka, dan peserta yang berpendidikan $\mathrm{S} 1$ ke atas akan menjawab sesuai dasar ilmu teori.

JPR \#2: Biasanya orang yang memiliki tanah, bukan yang penggarap tanah, mampu menyambung konsep ilmu dan hak milik tanah karena pandangan politik dan ekonomi mereka. Tambahan ilmu memain peran yang lebih besar dari pada hak milik tanah dalam pembentukan IPPHTI. Mayoritas responden tidak mampu menyambung konsep ilmu dan hak milik tanah. Orang yang berstatus tinggi dalam IPPHTI bisa melihat hubungannya.

JPR \#3: Pendapat yang muncul dari diskusidiskusi adalah apabila pelatihan SDM tersedia, maka sumberdaya ekonomi dari pemerintah dan swasta serta penelitian universitas akan lebih baik dimanfaatkan yang dilatih SL. Memperoleh informasi yang secara konkret dapat memperbaiki penghidupan petani selalu menjadi tujuan utama dari IPPHTI.

\section{Kesimpulan}

Jawaban-jawaban dari Pertanyaan Reset \#1 dan \#3 rupanya sesuai pengetahuan reset yang sudah ada (FAO, 2001). Tetapi JPR \#2 tentang hubungan di antara ilmu dan hak milik tanah minta diteliti lagi. Mengapa ada kesulitan dari para petani untuk melihat hubungannya? Mengapa hanya orang yang memiliki tanah yang mampu memahaminya? Mungkin kemampuanya muncul dari pandangan politik dan ekonomi mereka? Ada kekurangan pikiran kritis para responden? Tindakan kolektip (Friere, 1970) memerlukan kesadaran dan pikiran kritis (Habermas in Parks, 1993).

\section{Rujukan}

Bunch, R. (2000) Two Ears of Corn. Oklahoma City, OK: World Neighbors

CIP-UPWARD (2003). International Potato Center through the User's Perspective with Agricultural Research and Development, Philippines, International Learning Workshop on
Farmer Field Schools (FFS): Emerging Issues and Challenges, 2125 October, 2002, Yogyakarta, Indonesia. A compilation of workshop discussion:

http://www.eseap.cipotato.org/upward/ abstract/FFSBook2003.htm

Dilts, R. (2001). From Farmer Field Schools to Community IPM: Scaling up the IPM Movement. LEISA Magazine (Low External Input Sustainable Agriculture), posted March 2001: http://www.ileia.org/2/17-3/18-21/pdf

FAO (2001). 10 Years of Building Community from FFS to Community


Bartlett, A., Jakarta, Indonesia: http://communityipm.org/docs/10years ofipm/10years-main.htm

FAO SD Pages (1999). Small Farmer Group Associations: Bringing the Poor Together, an email conference sponsored by the FAO Sustainable Development (SD) Dimensions Pages: http://www.fao.org/sd/PPdirect/ppfo00 $\underline{02 . h t m}$

Friere, P. (1970). Pedagogy of the Oppressed. New York, NY: Continuum Publishing

Huck, S. (2000). Reading Statistics and Research, 3rd ed. New York, NY: Addison Wesley Longman

IPPHTI (2000). The Ikatan Petani Pengendalian Hama Terpadu Indonesia (Farmer IPM Association of Indonesia), Toxic Trail website: http://www.communityipm.org/toxictr ail/issue7-Associations.htm

IPPHTI (2001). IPPHTI, West Java Conference IV, Ciamis, West Java, Indonesia, 27-30 May 2001

Mathias, E. (1996). Recording and Using Indigenous Knowledge: A Manual. Silang, Cavite, Philippines: International Institute for Rural Reconstruction 
Park, P. (1993). Voices of Change, Participatory Research in the United States and Canada, edited by Park, P.: Westport, CT, Brydon-Miller, M., Hall, B., and Jackson, T., Bergen and Garvey publishers

Patton, M. (1997). Utilization-Focused Evaluation, The New Century Text, $3^{\text {rd }}$ Edition. Thousand Oaks, CA: Sage Publications, Inc.

Uphoff, N. (1998). A field methodology for participatory self-evaluation of PPP group and inter-group association performance. Human Resources, Institutions and Agrarian Reform Division, Food and Agriculture Organization of the United Nations, May 1989 ,

http://www.fao.org/sd/ppdirect/ppre00 59.htm, posted June 1998 